\title{
معرفة الزراع بالممارسات المتعلقة بترشيد استخدام المبيدات والأسمدة الكيماوية ببعض قرى محافظة الثرقية
}

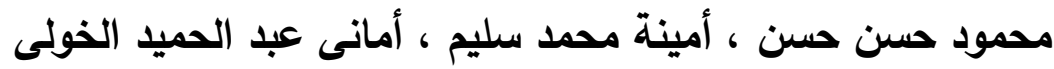 \\ قسم بحوث المجتمع الريفى، معهد بحوث الإرشاد الزراعى والتتمية الريفية، مركز البحوث الزراعية عائي
}

Received: Nov. 12, 2017

Accepted: Nov. 19,2017

الملخص

إستهاف البحث التعرف على مستوى معرفة الزراع بالممارسات المتعلقة بترشيد استخدام المبيدات والأسدة الكيماوية، وكذا التعرف على العلاقة بين درجة معرفتهم بتلك المدارسات وبعض خصائصهم الشخصية والإجتماعية والإقتصادية، والتعرف على أسباب نقص تلك الدعرفة، وقد أجرى البحث على عينة قوامها 90 مبحوث، تم إختيارهم عشوائياً من ثلاث قرى ولته بدحافظة الثرقية، وتم تجميع البيانات خال شهرى سبتمبر وأكتوبر 2017 بالدقابلة الثخصية بواسطة إبتمارة مقالبة بعد إختبارها مبئيًا

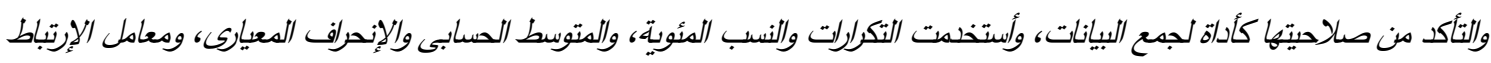

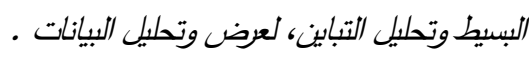
وقد توصل البحث إلى النتائج الآتية: 1- تبين أن 64,4٪ من المبحوثين لليهم مستوى معرفة متوسط بالمعارسات الهتعلقة بترشيد استخدام الأسدة الكيهاوية، و

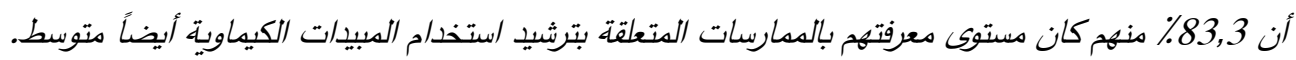
2- وجود علاقة إرتباطية معنوية موجبة بين درجة معرفة المبحثين بالمدارسات المتعلقة بترشيد إستخدام الأسدة والمبيدات

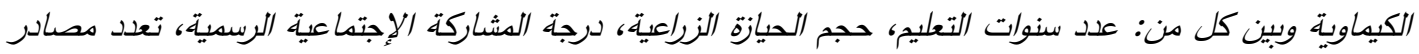
الدعلومات،التعرض لوسائل الإعلام، درجة الدشاركة فى الأنثطة الإشادية، فى حين تبين وجود علاقة إرتباطية

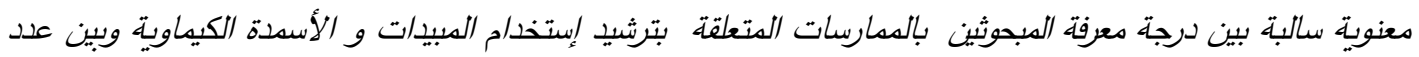
سنوات الخبرة فى العدل الزراعى. 3- تبين أن المتغيرات المستقلة مجتمعة تضسر 61,9٪ من التباين الكلى فى درجة معرفة المبحوثين بالمعارسات المتعلقة

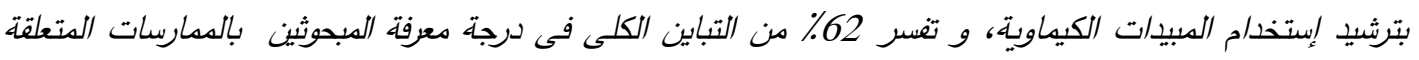
بترشيد إستخدام الأسدة الكيماوية.

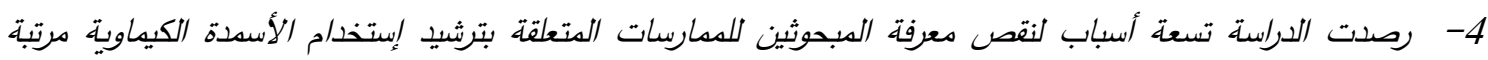

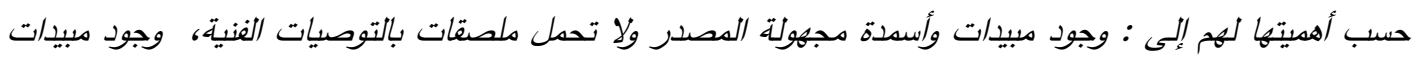

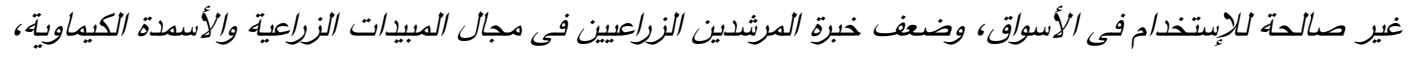

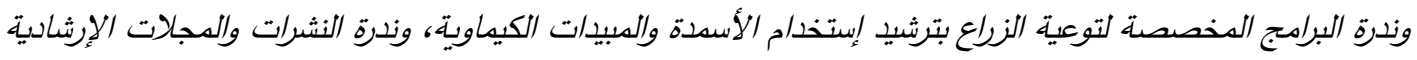
التى توفر الدعلومات الصحيحة عن ترشيد إستخدام الأسدة والمبيدات الكيماوية. ويوصى البحث بضرورة إهتمام جميع أجهزة الدولة الصحية والرقابية والإعلامية والبحث العلمى وعلى أسهرم الجهاز

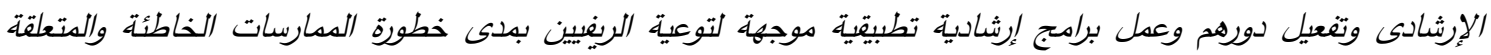

$$
\text { بترشيد اسنخدام المبيد/ت والأسدة الكيماوية. }
$$

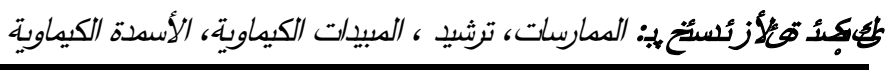


البيئة من أضرار وتلوث كيميائى أصاب الأخضر

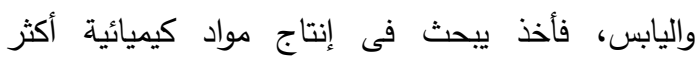

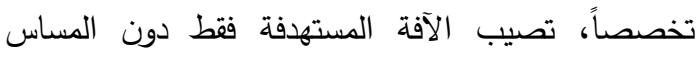
بالأحياء الأخرى ، وتكون سريعة التحلل حتى لا تتخلف الهان

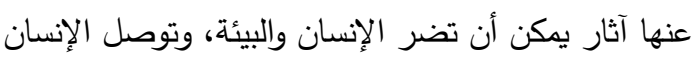
بذلك إلى أساليب جديدة لمقاومة الآفات مثل المقاومة

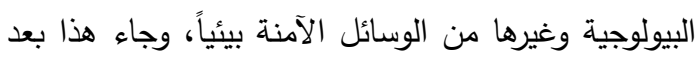
أن تعالت تحذيرات الخبراء والحكماء ضد إطلاق المزيد الإنياء

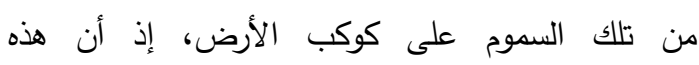

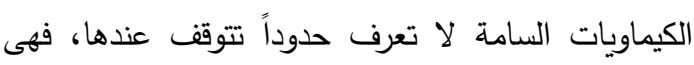
تتتقل بواسطة الماء والهواء وسلاسل الغذاء، إلى مسافات

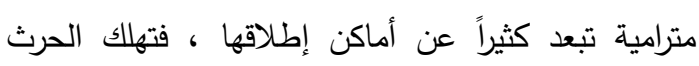
والنسل فى مناطق أخرى لم تشهد أو تسمع عنها شيئاً. ولقد تزايد استخدام المبيدات فى العقود الأخيرة

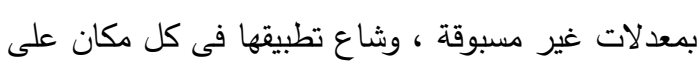

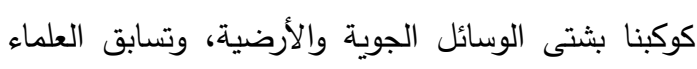

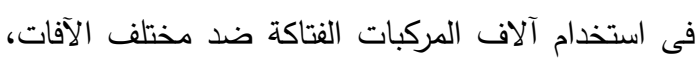

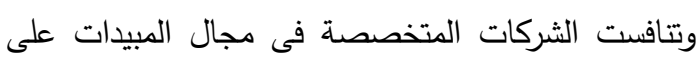
إنتاج أكثرها فاعلية ، وطرحها فى الأسواق العالمية، وتجد الجدال العيل

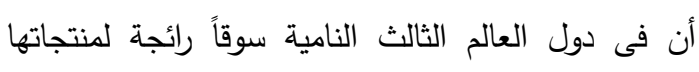
السامة، دون مراعاة لسلامة البيئة فى هذه الدول، مما لـال

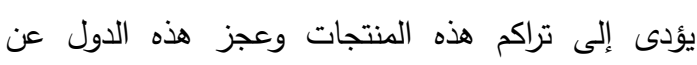
التخلص منها بالطرق الآمن، ومن جهة أخرى وبتزايد

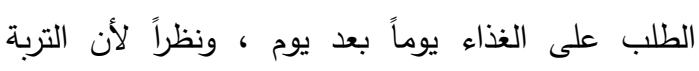

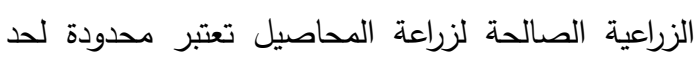

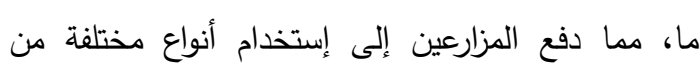

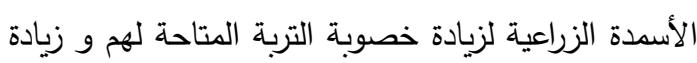
إنتاجها من المحاصيل المختلفة ، ولكن كثرة إستخدام تلك لكأل

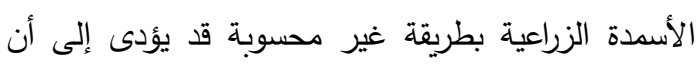

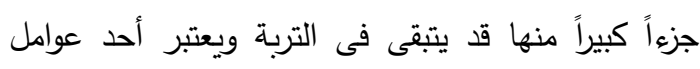
تلوث التربة الزراعية ، ويسبب كثير من الأضرار للبيئة المحيطة بهذه التربة، (إبراهيم، 2009).
المقدمة والمشكلة البحثية:

منذ أن عرف الإنسان الإنتاج الزراعى لتوفير

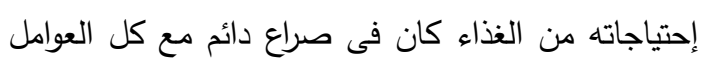

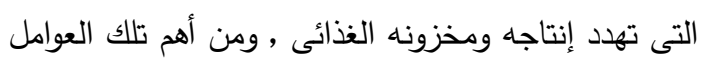

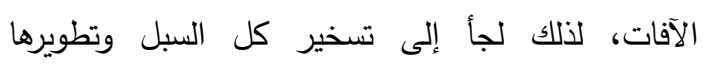

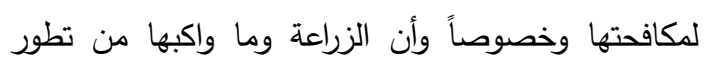

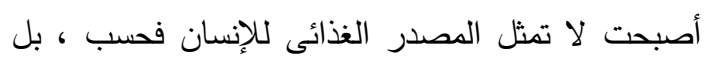

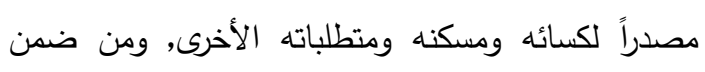

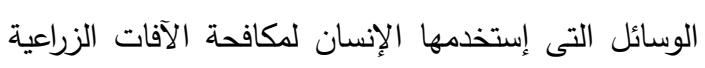

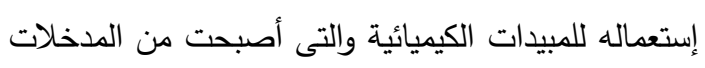

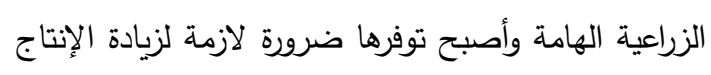
الزراعى، فبعد الحرب العالمية الثانية تركزت مكافحة

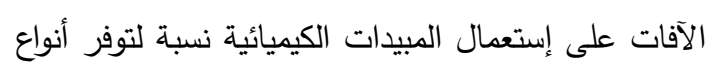

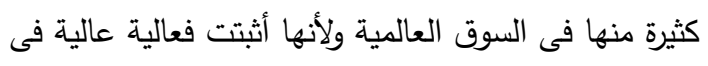
مكافحة الآفات. والحقيقة أن المبيدات قد لعبت دوراً كبيراً فى توفير

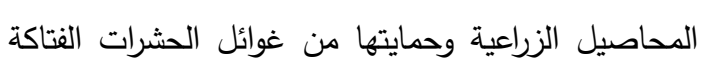
والحشائش الضارة، وغيرها من الآفات الزراعية التى تهاجم

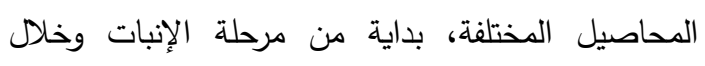
أطوار النمو و إنتاج الثمار والبذور ، وحتى فى أثناء نقلها

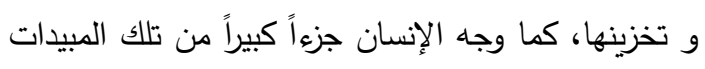

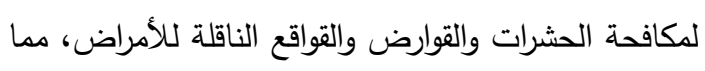

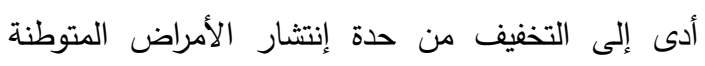

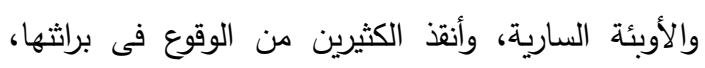

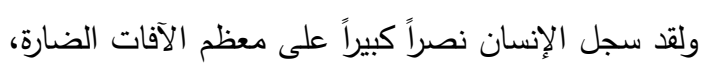

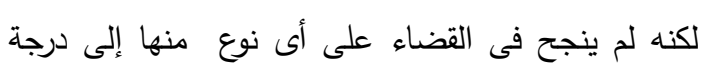

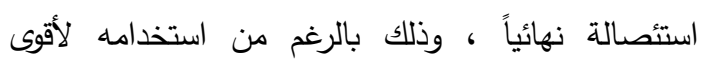

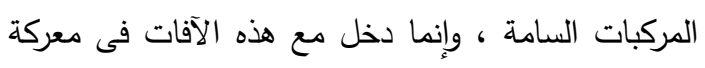

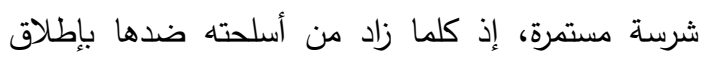
كميات مركزة من المبيدات ولعدة مرات فى الموسم الواحد،

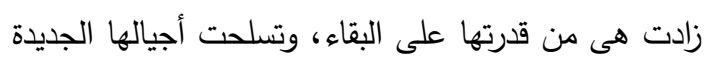

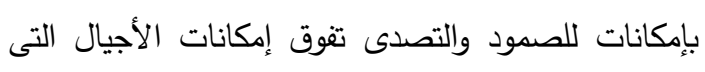

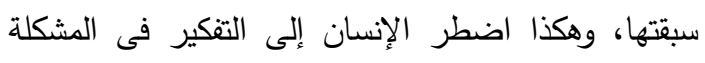

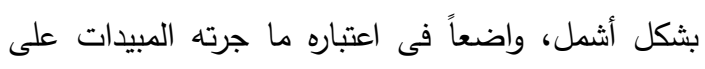


موجود فى البيئة وكانت النتيجة أن العديد من الحشرات

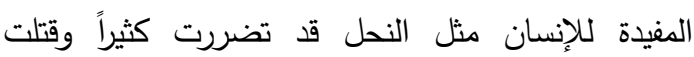

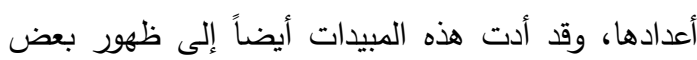

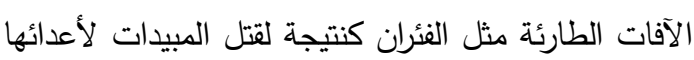

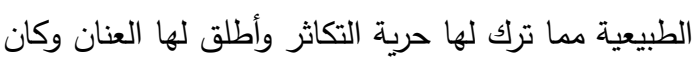
ذلك نتيجة مباشرة لإختفاء الحدأة المصرية، (القصاص،

وتؤكد "إيمان" أن أهم أسباب الإفراط فى الأسمدة

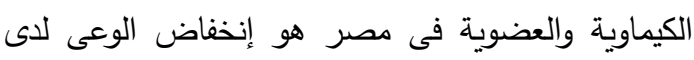

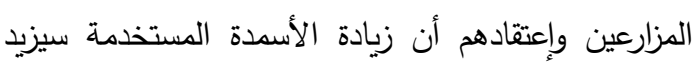

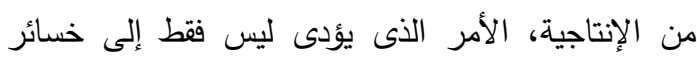

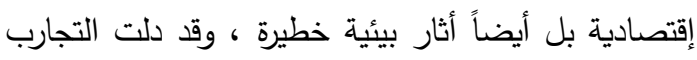

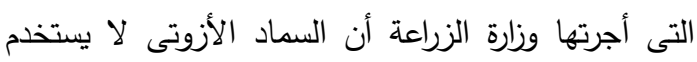

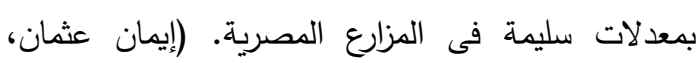
. (2009

ومما سبق يتضح أن ترشيد إستخدام الأسمدة

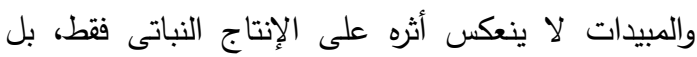
يتعداه إلى الإنتاج الحيوانى، وذلك عن طرئ لإنتاج لإنى الأعلاف

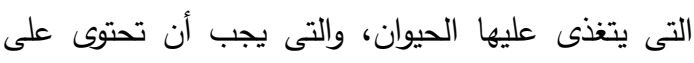

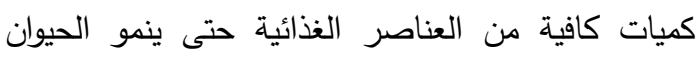

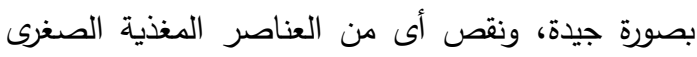
بالأعلاف يؤدى إلى ظهور أعراض مرضية على الفي الحيوان

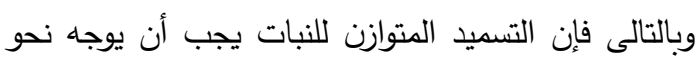

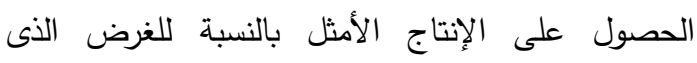

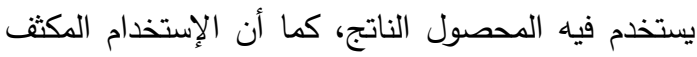

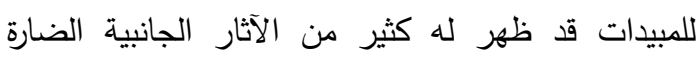

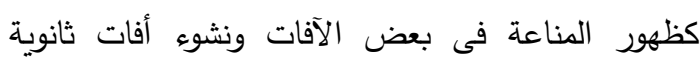

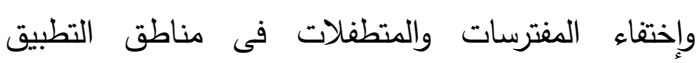
المكثف للمبيدات، إضافة إلى تسم المتعاملين فى الحقل فئل

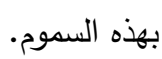

ولذلك يجب أن يكون المزارع على معرفة كاملة بأهمية

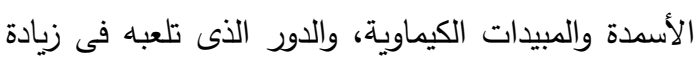
الإنتاج وتحسين نوعيته، وفى نفس الوقت يجب الأن أن يعلم الأضرار التى يمكن حدوثها للبيئة نتجة سوء إستخدامه لونه
ويرى "الغنام أن الإستخدام المفرط فى الأسمدة يترتب

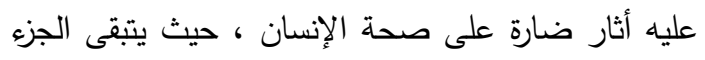

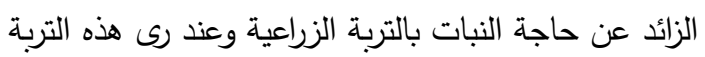

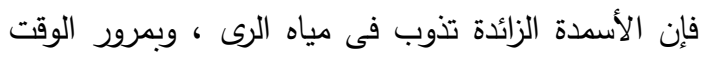

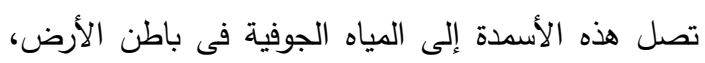

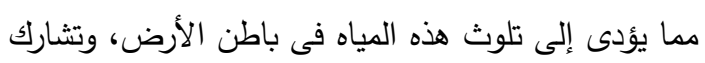
الأمطار مياه الصرف الزراعى والمياه الجوفية فى نقل الأل الأل

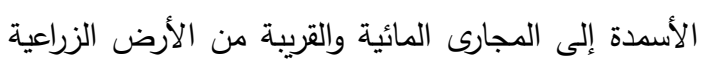

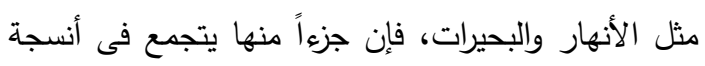
النبات بنسبة عالية ويصل تأثيرها الضار إلى الإنسان

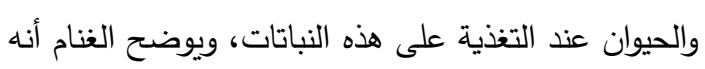

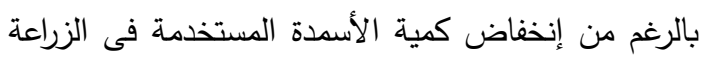
فى مصر خلال التسعينات (نصيب الهكتار 347 كيلو

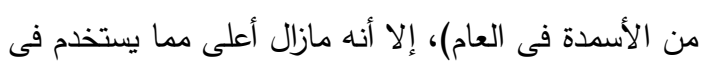

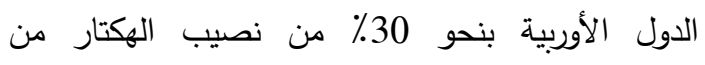

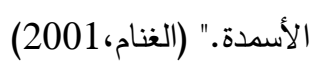
وعلى الرغم من أن الأرض الزراعية تعتبر مورداً هاماً

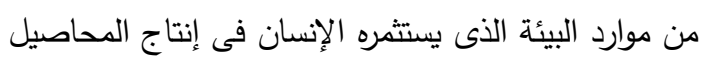

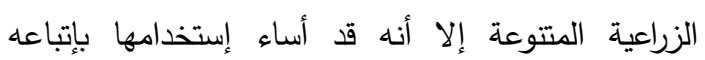
الممارسات الخاطئة التى تؤدى إلى تدهورها وإنهاكها

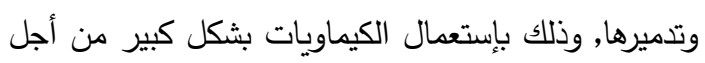

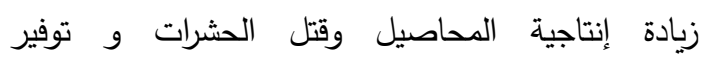
الإحتياجات الغذائية إلا أن الإستخدام المفرط الذى يحدث

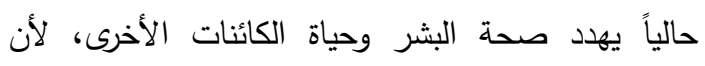
إستخدام المبيدات لا تقتصر على المنطقة التى تستخدم

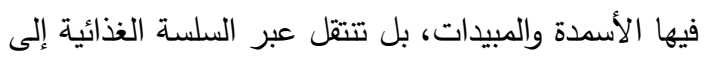

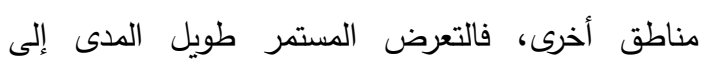

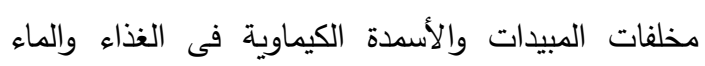
وحتى فى الهواء ينطوى على مخاطر كبيرة ويؤدى لقتل

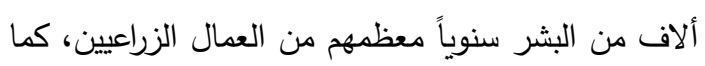

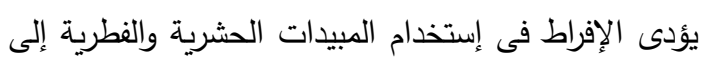
إختلال التوازن البيئى فى العلاقات الطفيلية بين الآفات والأعداء الطبيعية لها حيث أن معظم المبيدات الكيماوية

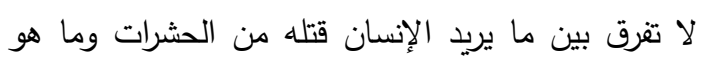




\section{Hassan, et al.,}

الإستفادة من نتائج البحث فى تطوير البرامج الإرشادية والتتموية

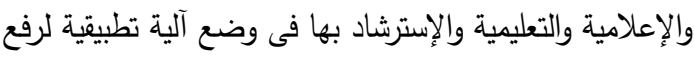
مستوى معرفة الزراع بالممارسات المتعقة بترشيد استخدام المبيدات والأسمدة الكيماوية ووضعها أمام منفذى السياسات للإستعانة بها فى وضع برامج تدريبية لزيادة معرفة الزراع

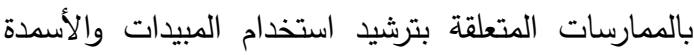
الكيماوية، و التى تستهدف تتمية سلوكهم الإيجابى للبيئة، والحد

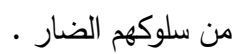

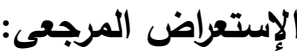

لقد أوضحت المعلومات الصادرة من منظمة الصحة العالمية أن كمية المبيدات المستخدمة فى مكافحة الآفات فى تزايد مستمر خاصة فى الدول النامية ومن بينها الدول العربية, كما أثبتت الممارسة العملية فى العديد من الدول

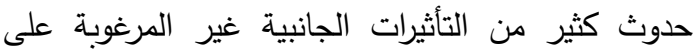
صحة الإنسان والحيوان والبيئة نتيجة للإستخدام الدكثف للمبيدات لذلك إهتمت معظم الدول والمنظمات العالمية بوضع القوانين والتشريعات والخطوط التوجيهية التى تنظم

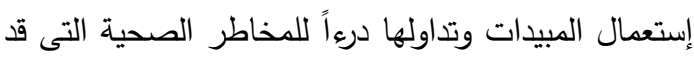
تحدث للإنسان والحيوان والبيئة نتيجة لسوء لإستخدامها. (المنظمة العربية للتنمية الزراعية، 1996). وذكر "أرناؤوط" أن المبيدات هى مواد كيماوية تستخدم فى مجالات الزراعة والصحة العامة بقصد القضاء على الآفات سواء كانت حشرات مثل دودة ورق القطن وغيرها أو أمراض أو حشائش أو الطفيليات التى تهدد صحة الإنسان والحيوان ويقع ضمن هذا التعريف منظمات النمو،

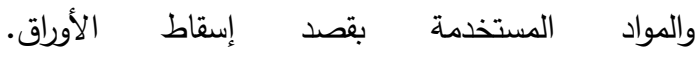
(أرناؤُط، 1999:239). ويلجأ الإنسان إلى إستخدام المبيدات فى الحالات التالية: 1- عند فثل طرق الدكافحة الأخرى الأكثر أمناً

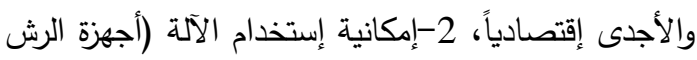

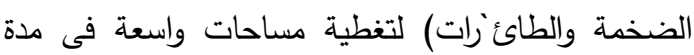
قصيرة، 3- هى الطريقة الوحيدة الفعالة فى حالة الظهور

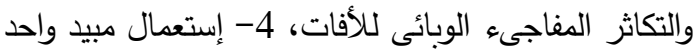

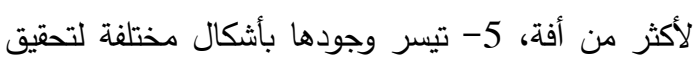

لها، و هذا لن يحدث إلا عن طريق الإستخدام الأمثل بواسطة المزارع، وإرشاده إلى ذلك، مدخلين فى الإعتبار إتجاهاته الثقافية والفكرية.

ومن العرض السابق فإن مشكلة البحث تتركز فى الإجابة على التساؤلات التالية: 1- ما هو مستوى معرفة الزراع بالممارسات المتعلقة

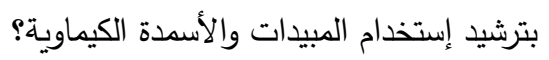
2- ما هى العلاقة بين العوامل المؤثرة على معرفة الزراع بالممارسات المتعلقة بترشيد إستخدام المبيدات والأسمدة الكيماوية؟ 3- ما هى أسباب نقص معرفة الزراع بالممارسات المتعلقة بترشيد إستخدام المبيدات والأسمدة

$$
\text { الكيماوية؟ }
$$

وللإجابة على هذه التساولات وضعت الأهداف الآتية: أهـداف البحث:.

1-التعرف على مستوى معرفة الزراع بالممارسات المتعلقة

$$
\text { بترشيد إستخدام المبيدات الكيماوية. }
$$

2- التعرف على مستوى معرفة الزراع بالممارسات المتعلقة

$$
\text { بترشيد إستخدام الأسمدة الكيماوية. }
$$

3-التعرف على أهم المتغيرات المرتبطة بمعرفة الزراع بالممارسات المتعلقة بترشيد إستخدام المبيدات

$$
\text { والأسمدة الكيماوية. }
$$

4-التعرف على أهم أسباب نقص معرفة الزراع بالممارسات المتعلقة بترشيد إستخدام المبيدات

$$
\text { والأسمدة الكيماوية. }
$$

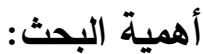

تتمثل الأهمية النظرية للبحث فى محاولة إلقاء مزيد من

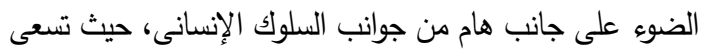

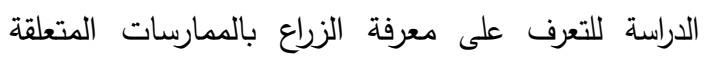

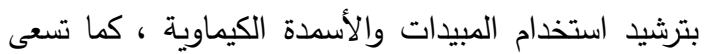
الدراسة إلى زيادة فهمنا عن طبيعة العلاقات بين معرفة الزراع بالممارسات المتعلقة بترشيد استخدام المبيدات والأسمدة الكيماوية وعدد من المتغيرات الإجتماعية والإقتصادية والثخصية، أما الأهية التطبيقية تتمثل فى مدى إمكانية 
النفسية نتيجة التعرض للكثير من الملوثات الزراعية،

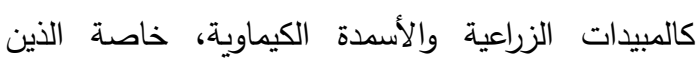

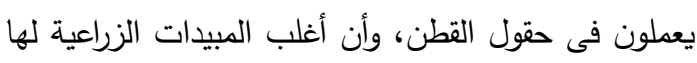

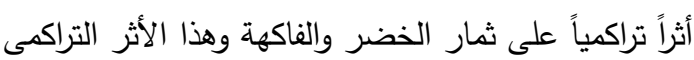

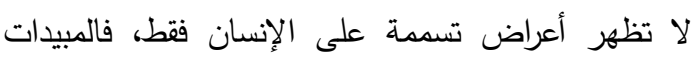
تؤثر أيضاً على نوعية ومظهر الثمار وجودتها وعلى سبيل

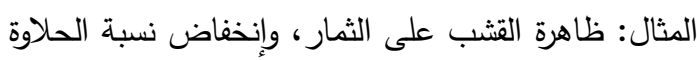
فى جذور بنجر السكر ، وحدوث ظاهرة التزرنخ والطعم

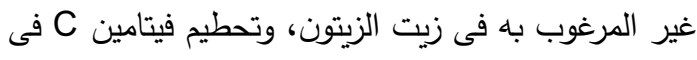

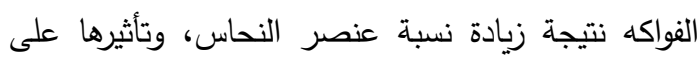

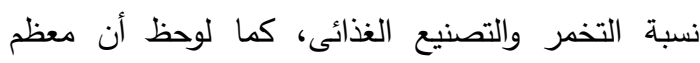

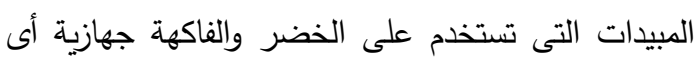
تمتصها الثمار وتتضج أجزائها بسرعة غير طبيعية نتيجة للرش العشوائى ، حيث وجد أن محتوى بعض محاصيل

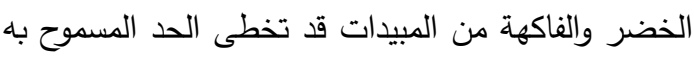

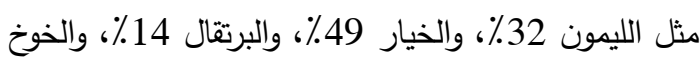
33\%، والكوسة 100٪ (عبدالصدد، 2013).

وأكد "الخولى" أن التلوث الناتج عن الإفراط فى

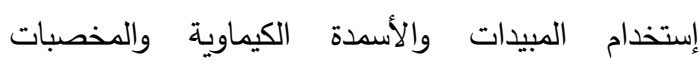

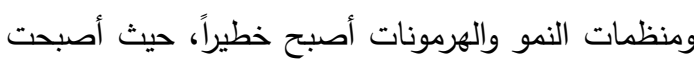
الزراعة المصرية حقل تجارب ومستباحة لإستخدام العديد

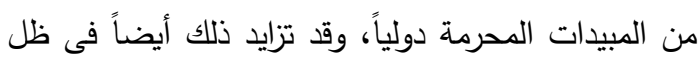

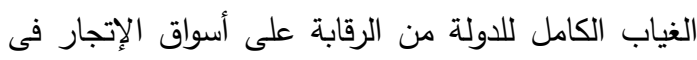

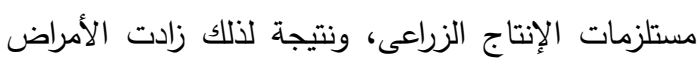

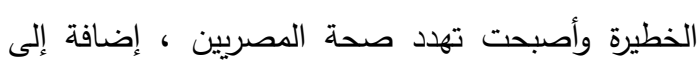

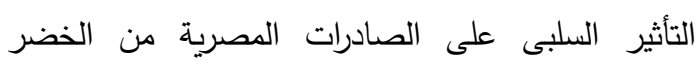

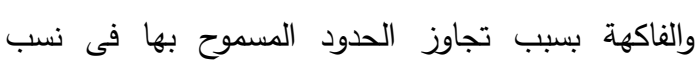
المتبقيات من المبيدات والأسمدة الكيماوية. (الخولى، لئل

وقد ذكر"عبد العال" نقلاً عن"صابر" أنه مع تطبيق

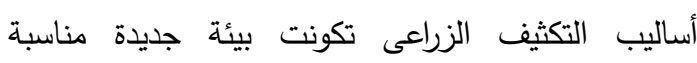

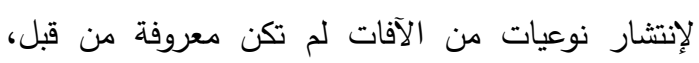

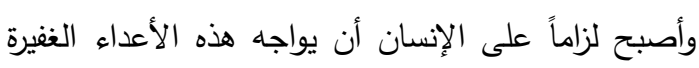

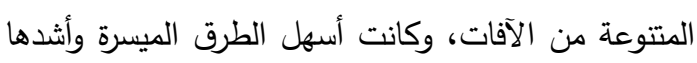

المكافحة بأماكن متباينة مثل تدخين الأماكن المغلقة وتطهيرها كصوامع الحبوب والمخازن وأيضاً الدفيئات

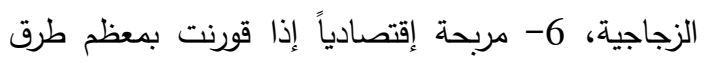

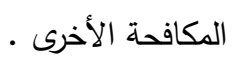
ولكن عيوب الإستخدام الواسع المتكرر لهذه المواد

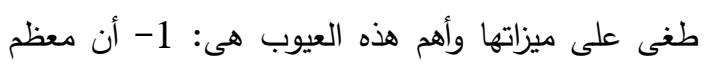

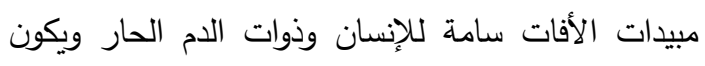

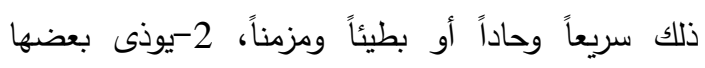

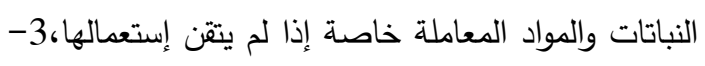
يقضى معظمها على الأفة وعلى أعدائها الحيوية كالمفترسات والمتطفلات فتسبب الإخلال بالتوازن الحيوى الإلى الحئ

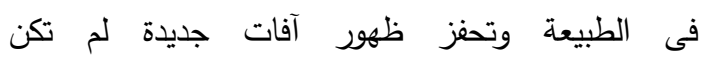
بالحسبان،4-بقاء الآثار السامة لبعض هذه المواد ولفترات طويلة فى عناصر البيئة الدختلفة كالغذاء والماء والتربة لئل

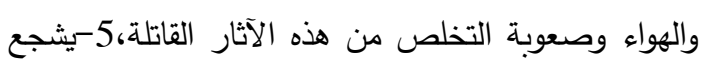
تكرار إستخدامها ظهور صفة مقاومة الآفات لمبيداتها

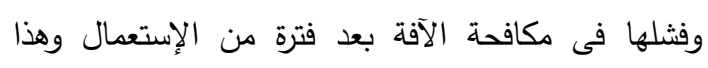

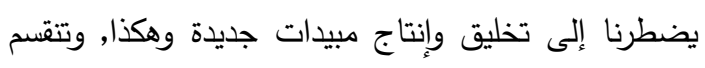

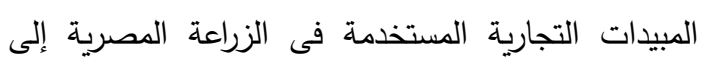
ثلاث أنواع رئيسية هى الحشرية والفطرية ومبيدات الحشائش، وقد بلغ عدد المبيدات المسجلة فى مصر فى رئل

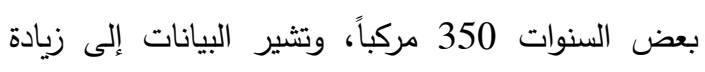
الكميات المستهلكة منها, ولقد ورد تقرير الصحة العالمية وتئي لتوضح الأثار السلبية المحتملة من إستخدام مبيدات الأفات وتلويثها للبيئة كما يتضح فى النقاط الأتية: تسرب البنات

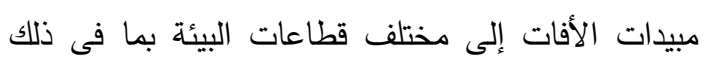

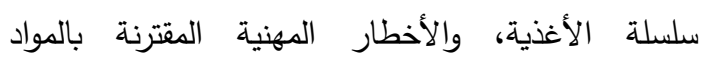
الكيماوية ذات الفعالية البيولوجية العالية، ونقل المبيدات وتخزينها وتعبئتها والتخلص منها بطرق غير صحيحة وسوء معالجة الفضلات الخطرة فى مصانع الإنتاج. (المنظمة العربية للتمية الزراعية، 1994) وذكر "عبد الصمد" نقلا عن "إسماعيل" أن الأطفال

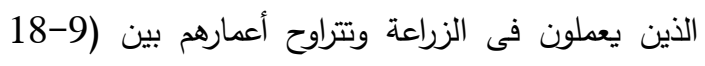
سنة) يتعرضون للعديد من الأمراض والكثير من الإطرابات الرمات بن 


\section{Hassan, et al.,}

الكيماوية، ومن أهم المصادر التى يستمد منها الزراع

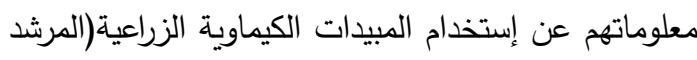

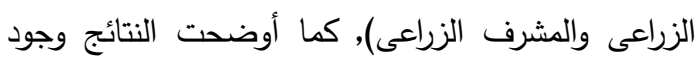

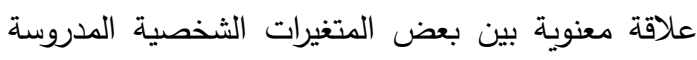

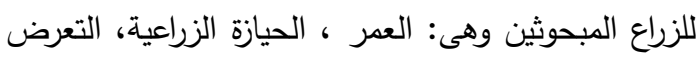

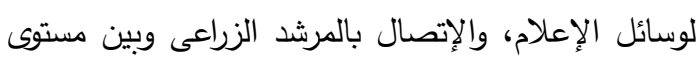
إدراكهم للتوصيات المتعلقة بإستخدام المبيدات الكيماوية

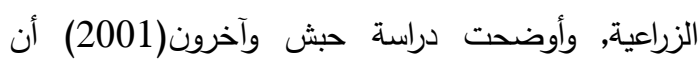

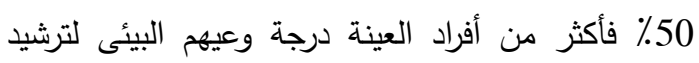

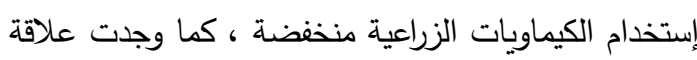
إرتباطية بين مستوى وعى الزراع نحو ترشيد إستخدام الكيماويات الزراعية والمتغيرات المستقلة الددروسة التالية:

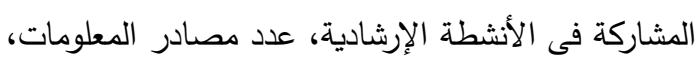

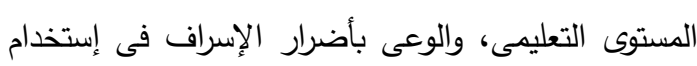

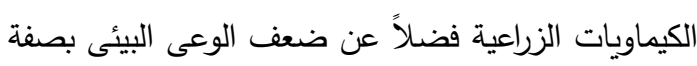
عامة.

\section{الطريقة البحثية:

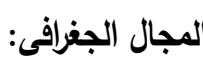

أجرى هذا البحث بمحافظة الثرقية، حيث تضم سبعة عشر الجرئ مركزاً وضم إليها حديثاً أربعة مدن جديدة، وتتميز المحافظة

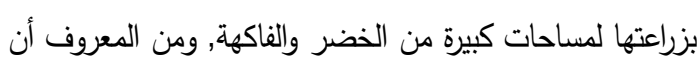
محاصيل الخضر والفاكهة أكثر عرضة للإصابة بالآفات

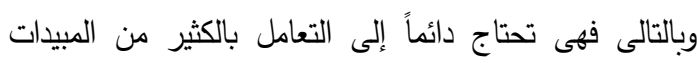

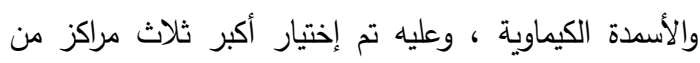
المحافظة منزرعة بالخضر والفاكهة ، فوقع الإختيار على مركز

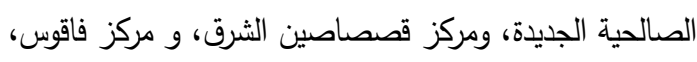
وعلى نفس المنوال تم إختيار قرية من كل مركز تكون الأكبر فى المساحة المنزرعة بالخضر والفاكهة، فكانت قرية السعيدية

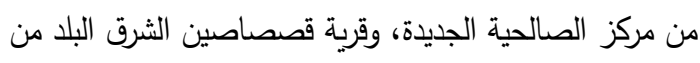
مركز قصصاصين الثرق ، وقرية سوادة من مركز فاقوس(مديرية الزراعة بالشرقية، 2017) - (2017)

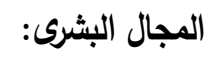
ومن واقع سجلات الحيازة فى كل جمعية زراعية من القرى البتري:
فتكاً بالآفات هى المهلكات الكيماوية، غير أن الآفات بصفة عامة والحشرات منها بصفة خاصة أظهرت تمرداً

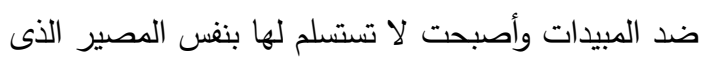

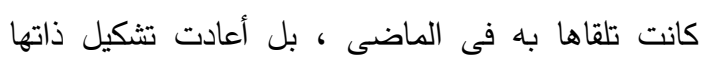

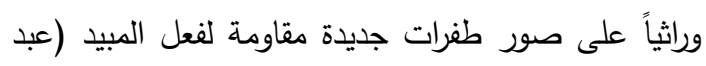

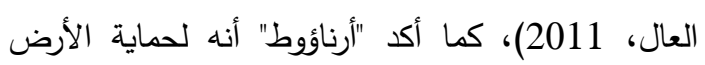

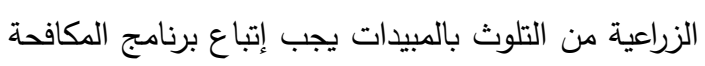
المتكاملة الذى يهدف إلى ترشيد إستهلاك المبيدات وحماية البيئة من التلوث عن طريق إنتخاب أصناف نباتية مقاومة

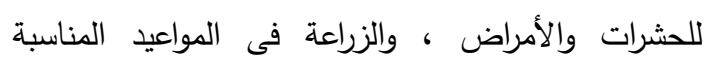
للمحاصيل، ومقاومة الحشائش ، وإستخدام الأعداء الحيوية

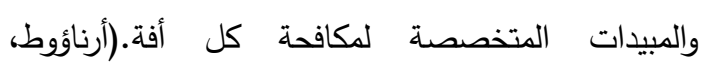

وأظهرت دراسة جويلى وأخرون (2004) أن هناك

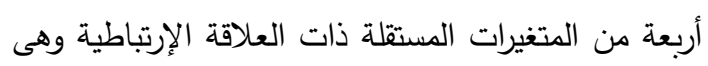

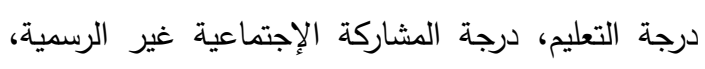

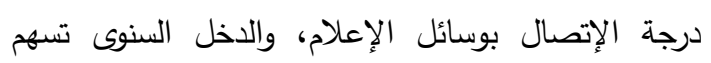

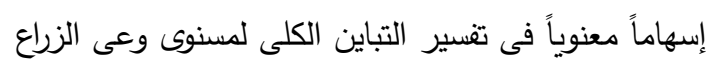

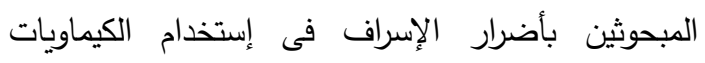

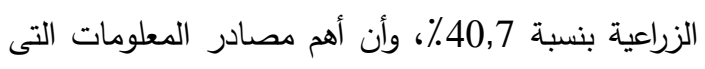
يستمد منها المبحوثين معلوماتهم عن الإستخدام الآمن

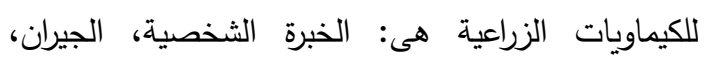

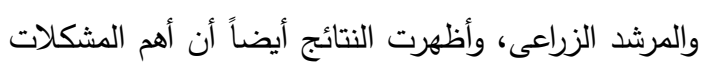

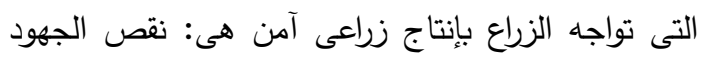

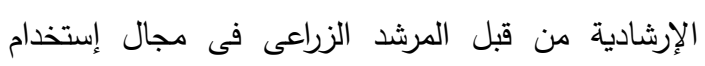

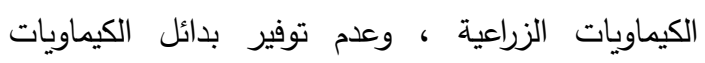

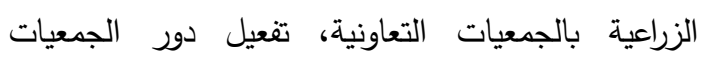

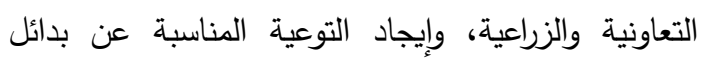

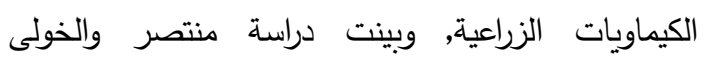
(1998) أن أكثر من نصف المبحوثين من الزراع بقليل

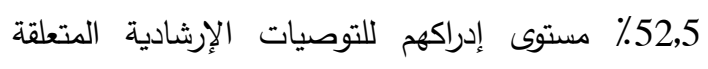
بإستخدام المبيدات الزراعية متوسط، وأن خمسهم مستوى الإنى

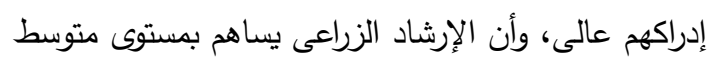
فى توعية الزراع المبحوثين بأساليب إستخدام المبيدات 
الإجابات هـى غير مشترك، عضـو عـادى، عضدو

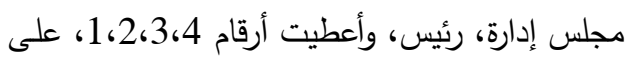

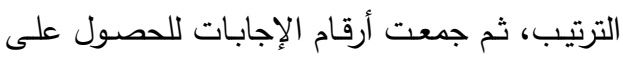

درجة المشاركة الإجتماعية الرسمية.

5- مصادر المعلومات عن الممارسات المتعلقة بترشيد

إستخدام المبيدات والأسمدة الكيماويـة: وتم قياسها

بعرض عدد من مصادر المعلومات فى هذا المجال

على المبحـوث ، وطلب منــه تحديـد نـوع مصسدر

معلوماته قى هذا المجال من خـلال إجابته بنعم أو ولو

لا، واعطيـت الإجابـات 2، 1 ، على الترتيـب، ثم

جمعـت ارقـام الإجابـات لتعبر عـن عـد مصـادر

المعلومات لدى المبحوث فى هذا المجال.

6- التعرض لوسائل الإعلام: وتم قياسها بعرض بعض

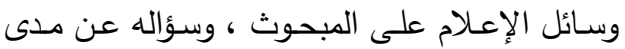

تعرضــه لهـذه الوسـائل فـى مجـال ترشيد اسـتخدام

المبيدات والأسمدة الكيماوية، وكانت فئات الإجابات

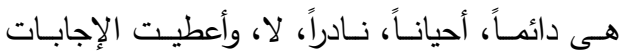

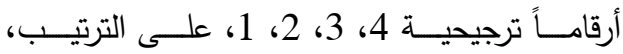

وجمعت لتعبر عن مدى التعرض لوسـائل الإعـلام فى هذا المجال.

7- المشـاركة فى الأنشطة الإرشـادية: وتم قياسـه بسؤال

المبحوث عمـا إذا كان شـارك فى أى نشـاط إرشـادى بالقرية وبأى درجة، لتكون إجابته دائماً، أحياناً، نادراً،

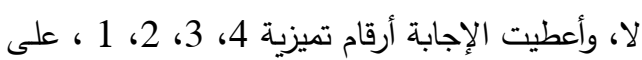

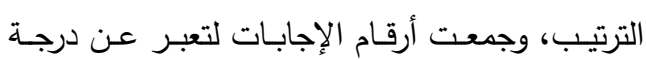
المشاركة فى الأنشطة الآرشادية.

8 - أسباب نقص معرفـة الـزراع بالممارسـات المتعلقـة

بترشيد استخدام المبيدات والأسـدمة الكيماويـة: وتم التعرف على درجة ترتيب هذه الأسباب بعرض بعض الترنيل أسباب نقص معرفة الزراع بالممارسات المتعلقة بترشيد

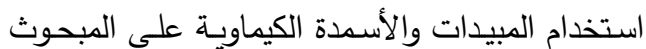
وطلب منه أن يعيد ترتيبها حسب الأكثر أهمية بالنسبة
الثلاثة المختارة تم تحديد عدد الحائزين بكل قرية ، فأسفر ذلك عن وجود 260 حائزاً بقرية السعيدية ، و255 حائزاً بقرية قصصاصين الشرق البلد ، و 375 حائزاً بقرية سوادة ، وبلغ وجلغ ولزيل إجمالى شاملة البحث 890 حائزاً، وتم إختيار 10٪ عشوائياً من هذه الشاملة لتمثل الثتلاث قرى ، وعليه تم توزيع هذا العدد حسب نسبة تمثيل كل قرية فى شاملة البحث، حيث كان عدد المبحوثين بقرية الصالحية الجديدة 26 مبحوث، و26 مبحوث بقرية قصصاصين الشرق البلد ، و 38 مبحوث بقرية سوادة وبذلك بلغ عدد المبحوثين 89 مبحوثاً. المنهج العلمى المستخدم فى الاراسة: أستخدم المنهج الوصفى لإجراء هذه الدراسة. جمع البيانات: جمعت البيانات من خلال المقابلة الشخصية بإستخدام إستمارة إستبيان، وقد تم جمع البيانات خلال شهرى سبتمبر وأكتوبر عام 2017.

قياس المتغيرات البحثية: أولاً : قياس المتغيرات المستقلة

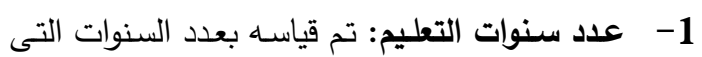

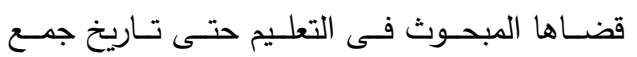

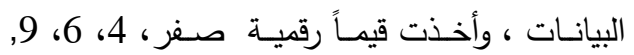

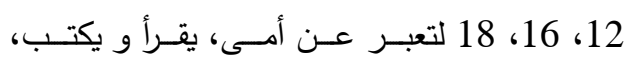
حاصـل على تعليم إبتدائى، تعليم إعدادى، تعليم متوسط، تعليم جامعى، وتعليم فوق جامعى، على الترتيب

2- إجمـالى الحيـازة الزراعيـة: تم التعبير عنهـا بحجم المساحة الزراعية لدى المبحوث بالقيراط. 3- عدد سنوات الخبرة في العمل الزراعى : تم قياسـه

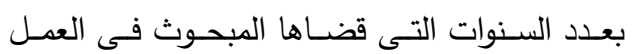
الزراعى حتى تاريخ جمع البيانات .

4- المشـاركة الإجتماعيـة الرسـية: تم قياسها بعرض بعـض المنظمـات والمؤسسـات الإجتماعيـة علـى لـى المبحـوث وسـؤاله عـن نـوع مشـاركته فيهـا، فكانـــ 


\section{Hassan, et al.,}

تلزم كل محصول؟، تعرف نوع الأسمدة الكيماوية التى

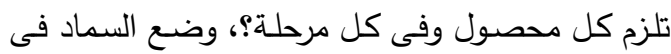
الدكان الصـيح تحت النبـات بيوفر عليك قد إيـه؟، تعرف إيه هى مخاطر الإسـراف فى إستخدام الأسمدة

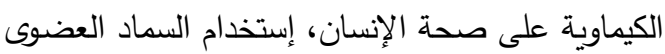
بديل الكيماوى أفضل لصحة الإنسان، يمكن الإستغناء

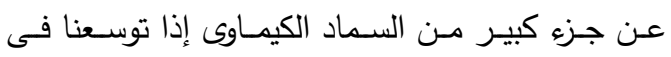
إستخدام السماد العضوى، السماد العضوى أفيد بكثير للمحصول ولقوام التربة من الكيماوى، تخزين الأسمدة

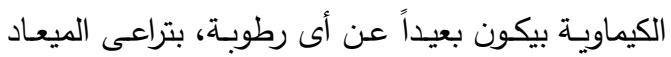
المناسب لوضع الكميات المناسبة من الأسمدة الكيماويـة

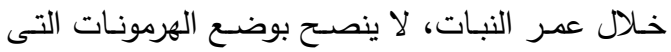
تؤدى إلى كبر حجم الثمار بصورة غير عادية، لتكون إجابته عالى، متوسط، لا يعرف ، وأعطيت الإجابات

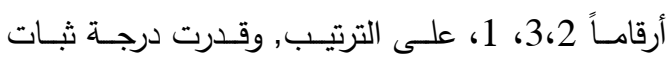
المقياس بإستخدام معامـل ألفـا فوجد أنـه

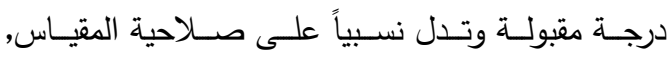
وجمعت درجات البنود العشرة للحصول على الدرجة الكلية لمعرفة الزراع بالممارسات المتعلقة بترشيد استخدام

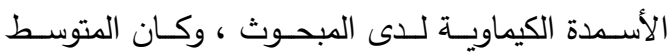
الحسابى قدره 24,98 درجة ، فى حين كان الإنحراف

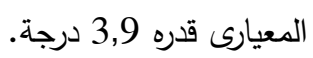

$$
\text { أساليب التحليل الإحصائى: }
$$

تم إستخدام التكرارات العددية والنسب المئوية والمتوسط الحسابى، لوصف البيانات، ومعامل الثبات ألفا للحكم على درجة ثبات المقاييس، ومعامل الإرتباط البسيط "لبيرسون" ومعامل الإنحدار لتحديد العلاقات بين متغيرات البحث.

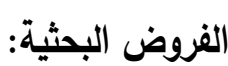

لتحقيق الهذف الثالث للدراسة تم صياغة الفروض البحثية الآتية: 1- توجد علاقة إرتباطية معنوية بين درجة معرفة الزراع بالممارسات المتعلقة بترشيد استخدام المبيدات الكيماوية و كل من المتغيرات المستقلة المدروسة على حده .
ثانياً: قياس المتغير التابع

وقد تم قياسه من خلال بعدين يعبران فى مجلهما عن معرفة الزراع بالممارسات المتعلقة بترشيد استخدام المبيدات والأسمدة الكيماوية حيث تم القياس على النحو التالى:

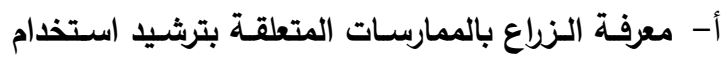

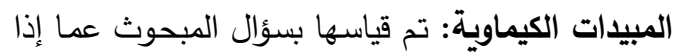
كان يعرف الممارسات المتعلقة بترشيد استخدام المبيدات الكيماويـة التالية: تحضير محلول الرش من المبيدات القابلة للبلل ، تحضير محلول الرش من المركزات القابلة

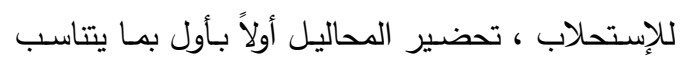
مـع المساحات المطلوب علاجها حتى لا يحدث فقد ،

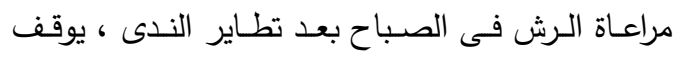
الرش عند إشتداد الحرارة خلال ساعات الظهيرة ، مراعاة ، براة عدم الرش للنباتات وهى فى حالة عطش مراعاة أن

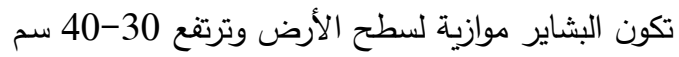

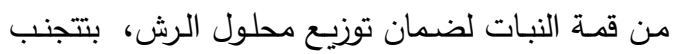

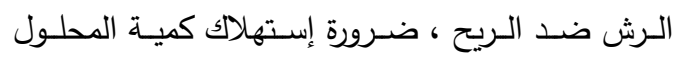
المقررة للمساحة، مراعاة عدم نقل المبيدات من عبوتها

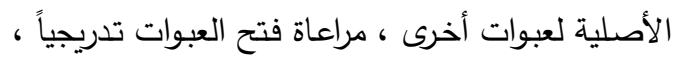
بتراعى عدم ملىء الرشاشة تماماً حتى الفوهة ، مراعاة

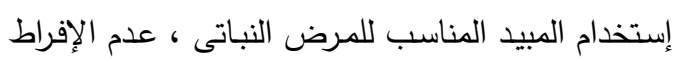

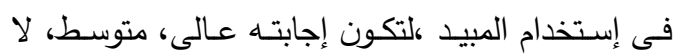

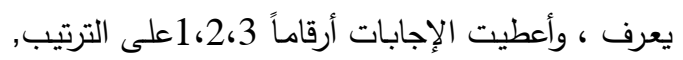

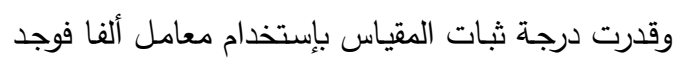

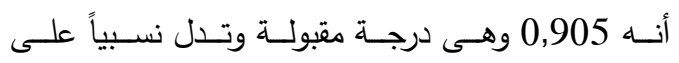
صلاحية المقياس, وجمعت درجات البنود الأربعة عشر ورج للحصول على الدرجة الكلية لمعرفة الزراع بالممارسات

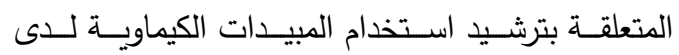
المبحوث, و كان المتوسط الحسابى قدره 32,34 درجة ، فى حين كان الإنحراف المعيارى قدره 5,7 درجة.

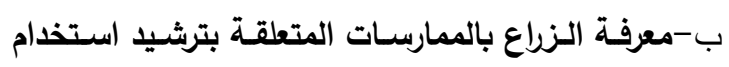

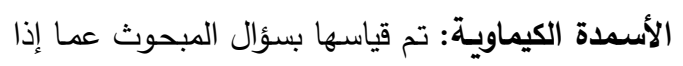
كان يعرف الممارسات المتعلقة بترشيد استخدام المبيدات

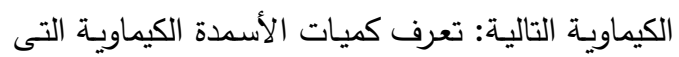


وصف خصائص المبحوثين:

تظهر نتائج جدول (1) أن أكثر من ربع المبحوثين

617,8 تعليمه جامعى ، وأن أكثر من نصف المبحوثين

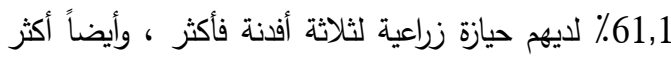
من نصفهم 54,5 \% لديهم خبرة فى العمل الزراعى لأكثر من

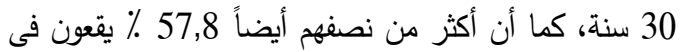
فئة مستوى التعرض لوسائل الإعلام المنخفض، وتبين أن أنمان

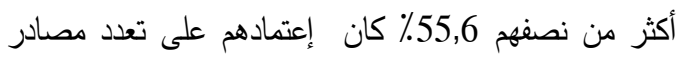

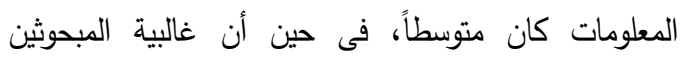
98,9\% مشاركتهم الإجتماعية الرسمية منخفضة، كذلك كان فين النية معظم المبحوثين 83,4\% مشاركتهم فى الأنشطة الإرشادية
2- توجد علاقة إرتباطية معنوية بين درجة معرفة الزراع

بالممارسات المتعلقة بترشيد استخدام الأسمدة الكيماوية و كل من المتغيرات المستقلة المدروسة على حده . 3- توجد علاقة إرتباطية معنوية بين درجة معرفة الزراع بالممارسات المتعلقة بترشيد استخدام المبيدات الكيماوية والمتغيرات المستقلة المدروسة مجتمعة. 4- توجد علاقة إرتباطية معنوية بين درجة معرفة الزراع بالممارسات المتعلقة بترشيد استخدام الأسمدة الكيماوية و المتغيرات المستقلة المدروسة مجتمعة . ولإختبار صحة الفروض البحثية السابقة تم وضع الفروض الإحصائية المناظرة لكل منها.

جدول رقم (1): توزيع المبحوثين وفقاً لخصائصهم الثخصية والإجتماعية

\begin{tabular}{|c|c|c|c|c|c|c|c|c|}
\hline$\%$ & التكرار & ال المتغير & $\%$ & | التكرار & 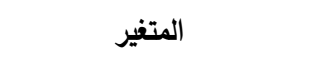 & $\%$ & التكرار & المتفير \\
\hline & & 6-التعرض لوسيائل الإعلام & & & 3-عدد سنوات العمل الزيراعى & & & 1-عدد سنوات التعليح \\
\hline 57,8 & 51 & ضعيف (من6-أقل من13) & 2,2 & 2 & (أقل من 10سنوات) & 20 & 18 & أمى (صفر سنة) \\
\hline 26,7 & 24 & متوسط (من13-أقل من19) & 43,3 & 39 & (من10سنوات -20سنة) & 18,9 & 17 & يقرأ ويكتب(4سنوات) \\
\hline \multirow[t]{3}{*}{15,5} & 14 & عالى(من19 فأكثر) & 54,5 & 49 & (أكثر من 20سنة) & 10 & 9 & إبندائى(6سنوات) \\
\hline & & 7-المشاركة فى الأنشطة & & & 4-المشاركة الإجتماعية & 6,6 & 6 & إعدادى(9سنوات) \\
\hline & & الإرنتادية & & & الرسبميك & & & \\
\hline 83,4 & 75 & ضعيفة (من9-أقل من13) & 98,9 & 89 & ضعيفة(من6-أقل من13) & 16,6 & 15 & دبلوم(12سنة) \\
\hline 14,4 & 13 & متوسطة (من13-أقل من19) & 1,1 & 1 & متوسطة (من13-أقل من19) & 27,8 & 25 & جامعى(16سنة) \\
\hline \multirow[t]{5}{*}{2,2} & 2 & عالية(من19 فأكثر) & 0 & $\mathbf{0}$ & عالية(من19 فأكثر) & & & 2-الحيازة الزراعية: \\
\hline & & & & & 5-تعلد مصادر المعلومات & 2,2 & 2 & أقل من فدان \\
\hline & & & 11,1 & 10 & ضعيفة(من9-أقل من13) & 36,7 & 33 & (من فدان - أقل من 3أفنة) \\
\hline & & & 55,6 & 50 & متوسطة (من13-أقل من16) & 61,1 & 55 & (من3أفندة فأكثر ) \\
\hline & & & $\mathbf{3 3}, \mathbf{3}$ & 30 & عالية(من16 فأكثر) & & & \\
\hline
\end{tabular}


استخدام المبيدات والأسمدة الكيماوية وكل من

المتغيرت المستقلة المدروسة على حده

لإختبار الفرض البحثى الأول للدراسة تم صياغة

الفرض الإحصائى الآتى: "لا توجد علاقة إرتباطية معنوية

بين درجة معرفة المبحوثين بالممارسات المتعلقة بترشيد إستخدام المبيدات الكيماوية وبين كل من المتغيرات التالية:

عدد سنوات التعليم، حجم الحيازة الزراعية، عدد سنوات الخبرة فى العمل الزراعى ، درجة المشاركة الإجتماعية الرسمية، تعدد مصادر المعلومات، التعرض لوسائل الترائل

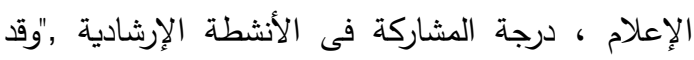
أستخدم فى إختبار هذا الفرض معامل الإرتباط البسيط،

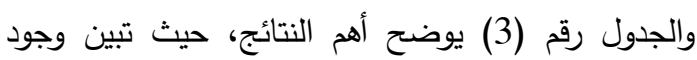
علاقة إرتباطية معنوية موجبة بين درجة معرفة المبحوثين بالممارسات المتعلقة بترشيد إستخدام المبيدات الكيماوية وبين كل من: عدد سنوات التعليم، حجم الحيازة الزراعية،

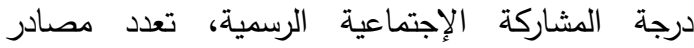

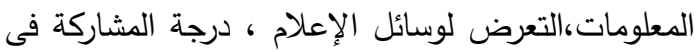
الأنشطة الإرشادية، حيث بلغت قيمة معامل الإرتباط بينهم 0,639، 0,522، 0,554، 0,629، 0,648، 0,653 على الترتيب، وهى جميعها عالية المعنوية عند مستوى 0,015، فئ، معنوية 0,01، فى حين تبين وجود علاقة إرتباطية معنوية سالبة بين درجة معرفة المبحوثين بالممارسات المتعلقة بترشيد إستخدام المبيدات الكيماوية وبين عدد سنوات الخبرة فى العمل الزراعى حيث بلغت قيمة معامل الإرتباط بينهما -0,31 ، مما يعنى أن زيادة عدد سنوات الخبرة فى العمل الإنل الزراعى لا يزيد من درجة معرفة المبحوثين بالممارسات المتعلقة بترشيد إستخدام المبيدات الكيماوية, وبذلك يمكن دئن رفض الفرض الإحصائى وقبول الفرض البحثى كلياً.
النتائج البحثية ومناقشتها

أولاً: مستوى معرفة المبحوثين بالممارسات المتعلقة بترشيد إستخدام المبيدات والأسمدة الكيماوية أوضحت نتائج الدراسة الواردة بجدول (2) أن غالبية المبحوثين 83,3٪ لايهم مستوى معرفة بالممارسات المتعلقة بترشيد إستخدام المبيدات الكيماوية متوسط، فى لئين حين أن1\% منهم يقعون فى فئة المستوى الضعيف ، لكن 15,6 من المبحوثين كان مستوى معرفتهم بالممارسات المتعلقة بترشيد إستخدام المبيدات الكيماوية مرتفعاً, كما لمان تبين أن ما يقرب من ثلثى المبحوثن 64,4٪ مستوى معرفتهر بالممارسات المتعلقة بترشيد إستخدام الأسمدة الكيماوية متوسط، فى حين أن الأقلية 2,2٪ منهم يقعون

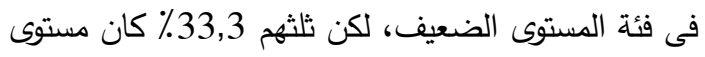

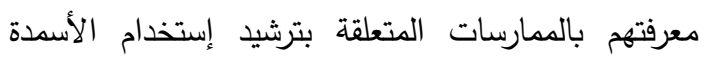

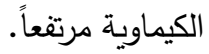

من العرض السابق للنتائج يتضح أن ما يقرب من

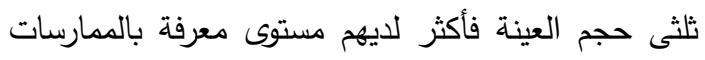

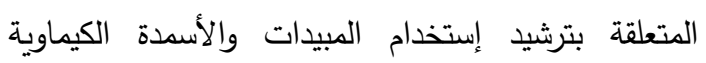
متوسط ، مما يؤكد أن هناك قصور لديهم يجب معالجته وبشكل سريع ، لما تمثله خطورة نقص تلك المعرفة على لهي

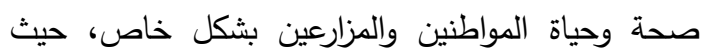
يرتيط ذلك بإنتشار أمراض خطيرة قد تؤدى فى أغلب ولب

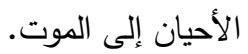

ثانياً: أ- العلاقة الإرتباطية بين درجة معرفة المبحوثين بالممارسات المتعلقة بترشيد

جدول رقم (2): توزيع المبحوثين وفقاً لمستوى معرفته بالممارسات المتعلقة بترشيد إستخدام المبيدات والأسمدة الكيماوية

\begin{tabular}{|c|c|c|c|c|c|}
\hline$\%$ & التكرار & المتعلقة بترشيد استخدام الأسمدة الكيماوية معرفة المبحوثين بالممارسات & $\%$ & 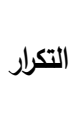 & 1 1-مستوى معرفة المبحوثين بالممارسات المتعلقة \\
\hline 2,2 & 2 & منخفض(من4-أقل من16 درجة) & 1,1 & 1 & منخفض(من4-أقل من22درجة) \\
\hline 64,4 & 58 & متوسط (من16-أقل من28 درجة) & 83,3 & 75 & متوسط(من22-أقل من39 درجة) \\
\hline $\mathbf{3 3}, \mathbf{3}$ & 30 & | مرتفع (من28-40 درجة) & 15,6 & 14 & مرتفع(من39-52 درجة) \\
\hline
\end{tabular}


درجة المشاركة الإجتماعية الرسمية، تعدد مصادر المعلومات، التعرض لوسائل الإعلام ، درجة المشاركة فى الإنى الأنشطة الإرشادية، حيث بلغت قيمة معامل الإرتباط بينهم 0,69، 0,459، 0,593، 0,655، 0,66، 0,645 على الترتيب، وهى جميعها عالية المعنوية عند مستوى معنوية 0,01، فى حين تبين وجود علاقة إرتباطية معنوية سالبة بين درجة معرفة المبحوثين بالممارسات المتعلقة بترشيد إستخدام المبيدات الكيماوية وبين عدد سنوات الخبرة فى دئه باله

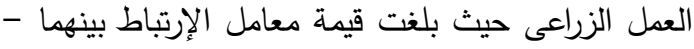

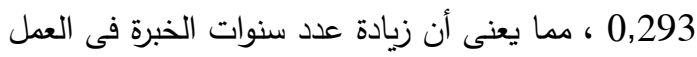

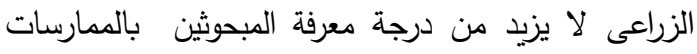
المتعلقة بترشيد إستخدام الأسمدة الكيماوية، وبذلك يمكن رفض الفرض الإحصائى وقبول الفرض البحثى كلياً.
ولإختبار الفرض البحثى الثانى للدراسة تم صياغة الفرض الإحصائى الآتى:"لا توجد علاقة إرتباطية معنوية بين درجة معرفة المبحوثين بالممارسات المتعلقة بترشيد إستخدام الأسمدة الكيماوية وبين كل من المتغيرات التالية : عدد سنوات التعليم، حجم الحيازة الزراعية،عدد سنوات الخبرة فى العمل الزراعى ، درجة المشاركة الإجتماعية

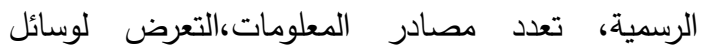
الإعلام، درجة المشاركة فى الأثشة الإرشادية ,"وقد أستخدم فى إختبار هذا الفرض معامل الإرتباط البسيط،

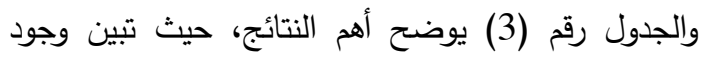
علاقة إرتباطية معنوية موجبة بين درجة معرفة المبحوثين بالممارسات المتعلقة بترشيد إستخدام الأسمدة الكيماوية وبين كل من: عدد سنوات التعليه، حجم الحيازة الزراعية،

جدول ( 3 ): العلاقة الإرتباطية والإنحارية بين خصائص المبحوثين المدروسة ودرجة معرفته بالممارسات المتعلقة بترشيد إستخدام المبيدات والأسمدة الكيماوية

\begin{tabular}{|c|c|c|c|c|c|}
\hline \multicolumn{2}{|c|}{ درجة معرفة الممارسات المتعلقة بترشيد } & \multicolumn{2}{|c|}{ درجة معرفة الممارسات المتعلقة بترشيد } & \multirow{2}{*}{ المتغيرات المستقلة } & \multirow{2}{*}{ ? } \\
\hline معامل الإنحدار & معامل الإرتباط & معامل الإنحدار & معامل الإرتباط & & \\
\hline$* 0,355$ & $* * 0,69$ & 0,201 & $* * 0,639$ & عدد سنوات التعليم & 1 \\
\hline$* * 0,207$ & $* * 0,459$ & **0 0,282 & $* * 0,522$ & حجم الحيازة الزراعية & 2 \\
\hline $0,047-$ & **0,293- & $0,089-$ & ***0,310- & عدد سنوات الخبرة فى العمل الزراعى & 3 \\
\hline 0 & $* * 0,593$ & $0,036^{-}$ & $* * 0,554$ & المشاركة الإجتماعية الرسمية & 4 \\
\hline$* 0,312$ & $* * 0,655$ & $* 0,301$ & $* * 0,629$ & تعدد مصادر المعلومات & 5 \\
\hline $0,208-$ & $* * 0,660$ & $0,089-$ & $* * 0,648$ & التعرض لوسائل الإعلام & 6 \\
\hline$* * 0,309$ & $* * 0,645$ & $* * 0,313$ & $* * 0,653$ & المشاركة فى الأنشطة الإرشادية & 7 \\
\hline 0,787 & & 0,787 & & $\mathrm{R}$ & \\
\hline 0,62 & & 0,619 & & R2 & \\
\hline$* * 19,084$ & & $* * 19,066$ & & ف & \\
\hline
\end{tabular}




\section{Hassan, et al.,}

والمتغيرات المستقلة المدروسة مجتمعة "، ولإختبار هذا الفرض تم تضمين المتغيرات المستقلة معاً فى نموذج تحليلى واحد بإستخدام تحليل الإنحدار الخطى المتعدد والحصول على النتائج الواردة بجدول رقم (3)، والتى لئى أظهرت أن المتغيرات المستقلة مجتمعة ترتبط بمعامل إرتباط متعدد قدره 0,787 مع درجة معرفة المبحوثين

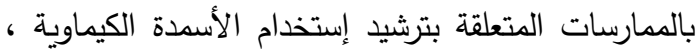

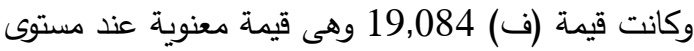

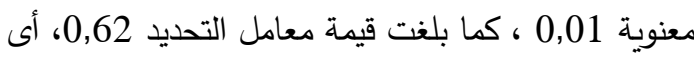
أن هذه المتغيرات المستقلة مجتمعة تفسر 62٪ من التباين الكلى فى درجة معرفة المبحوثين بالممارسات المتعلقة

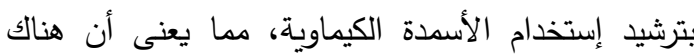

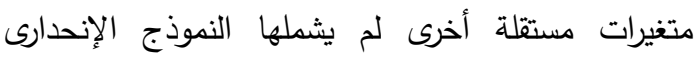
مسئولة عن تفسير 38٪ من التباين فى الدرجة الكلية لمعرفة المبحوثين بالممارسات المتعلقة بترشيد إستخدام

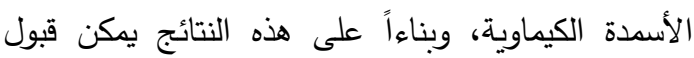
الفرض البحثى ورفض الفرض الإحصائى.

ثالثاً: أسباب نقص معرفة المبحوثين بالممارسات

\section{المتعلقة بترشيد الأسمدة والمبيدات الكيماوية}

ذكر 84,4 من المبحوثين أن سبب نقص المعرفة

لديهم بالممارسات المتعقة بترشيد استخدامهم للمبيدات

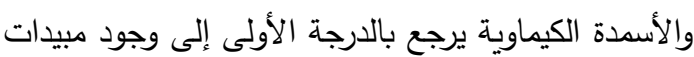

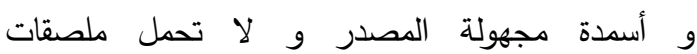
بالتوصيات الفنية، كما وضح 80٪ منهم أن السبب هو

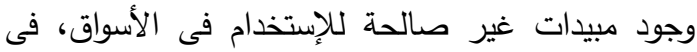

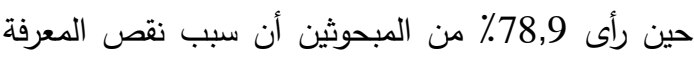
لديهج ناتج عن ضعف خبرة المرشدين الزراعيين فى مجال

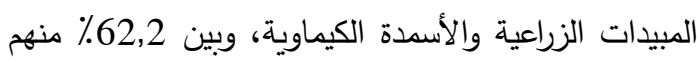
أن ندرة البرامج المخصصة لتوعية الزراع بترشيد إستخدام

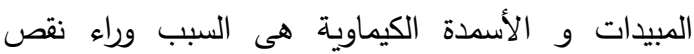
المعرفة لديهم، وأوضح أقل من نصف المبحوثين أن ندرة

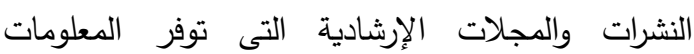
الصحيحة عن ترشيد إستخدام المبيدات والأسمدة الكيماوية
ب - العلاقة الإرتباطية بين درجة معرفة المبحوثين بالممارسات المتعلقة بترشيد استخدام المبيدات والأسمدة الكيماوية وكل من المتغيرت المستقلة

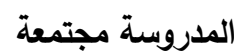

للتعرف على العلاقة الإرتباطية بين درجة معرفة المبحوثين بالممارسات المتعلقة بترشيد إستخدام المبيدات الكيماوية و المتغيرات المستقلة مجتمعة تم وضع الفرض البحثى الثالث فى صورته الإحصائية على النحو

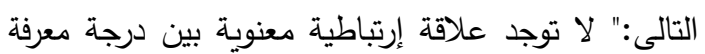
المبحوثين بالممارسات المتعلقة بترشيد إستخدام المبيدات الكيماوية و المتغيرات المستقلة المدروسة مجتمعة ", ولإختبار هذا الفرض تم تضمين المتغيرات المستقلة معاً فى نموذج تحليلى واحد بإستخدام تحليل الإنحدار الخطى لتصني

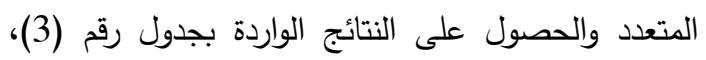

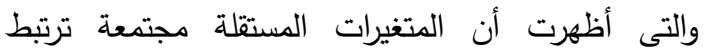
بمعامل إرتباط متعدد قدره 0,787 مع درجة معرفة المبحوثين بالممارسات المتعلقة بترشيد إستخدام المبيدات الكيماوية ، وكانت قيمة (ف) 19,066 وهى قيمة معنوية عند مستوى معنوية 0,01 ، كما بلغت قيمة معامل التحديد 0,619، أى أن هذه المتغيرات المستقلة مجتمعة تنسر 61,9٪ من التباين الكلى فى درجة معرفة المبحوثين

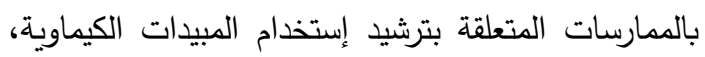
مما يعنى أن هناك متغيرات مستقلة أخرى لم يشملها النموذج الإنحدارى مسئولة عن تفسير 38,1٪ من التباين فى الدرجة الكلية لمعرفة المبحوثين بالممارسات المتعلقة

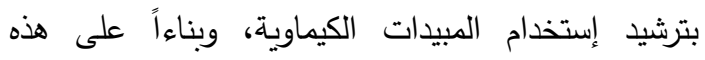

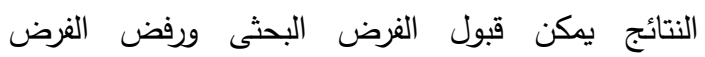
الإحصائى.

أما للتعرف على العلاقة الإرتباطية بين درجة معرفة

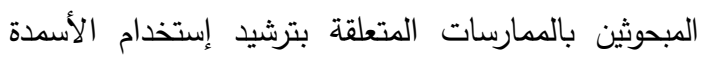

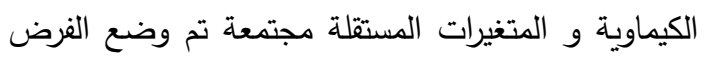

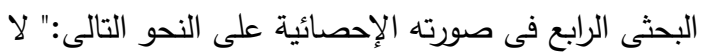
توجد علاقة إرتباطية معنوية بين درجة معرفة الدبحوثين بالممارسات المتعلقة بترشيد إستخدام الأسمدة الكيماوية 
والأسمدة الكيماوية يرجع وبشكل أساسى إلى أجهزة الدولة،

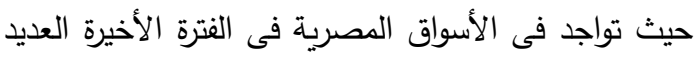

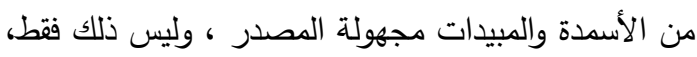
بل قد يمتد الأمر إلى كونها قد تكون مسرطنة وغير الآدير

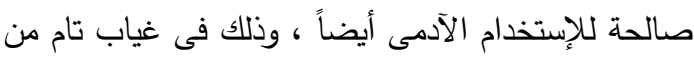

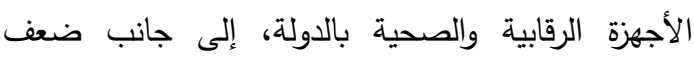
الجهاز الإرشادى فى توفير وإعداد مرشدين زراعيين متخصصين فى ذلك المجال ، تكون لديهم خبرة ودراية

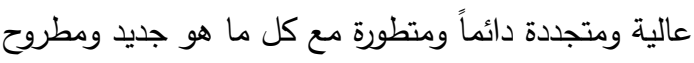
من مبيدات وأسمدة بالأسواق المحلية والدولية، كما تبين

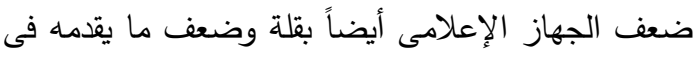

هذا الدجال.
كان هو سبب نقص معرفتهم بالممارسات المتعلقة بترشيد

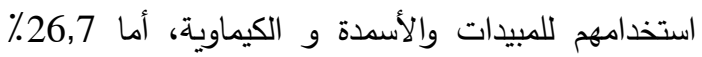
من المبحوثين فأقل ذكروا أن ندرة البرامج الإذاعية والتليفزيونية الموجهة للزراع عن ترشيد إستخدام المبيدات

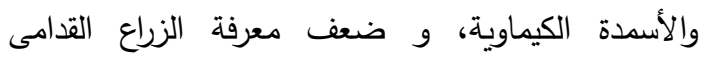

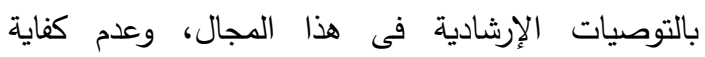
الحملات الإرشادية لتوعية الزراع بترشيد إستخدام المبيدات

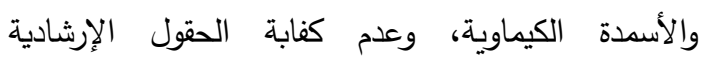

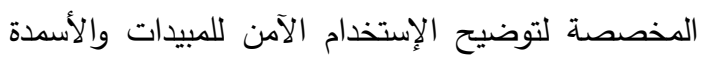

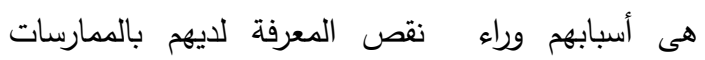
المتعلقة بترشيد استخدامهم لالمبيدات والأسمدة الكيماوية. من العرض السابق يتضح أن أسباب نقص معرفة

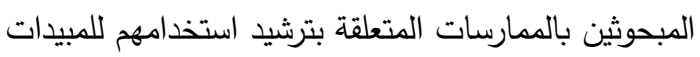

جدول رقم (4): توزيع المبحوثين وفقاً لأسباب نقص معرفتهم بالممارسات المتعقة بترشيد الأسمدة والمبيدات الكيماوية

\begin{tabular}{|c|c|c|c|c|}
\hline الترتيب & $\%$ & عدد & أسباب نقص معرفة المبحوثين بالممارسات المتعلقة بترشيد الأسمدة والمبيدات الكيماوية & م \\
\hline 1 & 84,4 & 76 & وجود مبيدات وأسمدة مجهولة المصدر ولا تحمل ملصقات بالتوصيات الفنية & 1 \\
\hline 2 & 80 & 72 & وجود مبيدات غير صالحة للإستخدام فى الأسواق & 2 \\
\hline 3 & 78,9 & 71 & ضعف خبرة المرشدين الزراعيين فى مجال المبيدات الزراعية والأسدة الكيماوية & 3 \\
\hline 4 & 62,2 & 56 & ندرة البرامج المخصصة لتوعية الزراع بترشيد إستخدام الأسمدة والمبيدات الكيماوية & 4 \\
\hline 5 & 45,6 & 41 & ندرة النشرات والمجلات الإرشادية التى توفر المعلومات الصحيحة عن ترشيد إستخدام الأسمدة & 5 \\
\hline 6 & 26,7 & 24 & ندرة البرامج الإذاعية والتليفزيونية الموجهة للزراع عن ترشيد إستخدام الأسمدة والمبيدات الكيماوية & 6 \\
\hline 7 & 23,3 & 21 & ضعف معرفة الزراع القدامى بالتوصيات الإلاثادية فى هذا المجال & 7 \\
\hline 8 & 12,2 & 11 & عدم كفاية الحملات الإرشادية لتوعية الزراع بترشيد إستخدام الأسمدة والمبيدات الكيماوية & 8 \\
\hline 9 & 6,7 & 6 & عدم كفابة الحقول الإرشادية المخصصة لتوضيح الإستخدام الآمن للأسمدة والمبيدات & 9 \\
\hline
\end{tabular}


الشرقية"، رسالة دكتوراة، كلية الزراعة ، جامعة

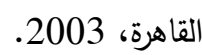

6- المنظمة العربية للتمية الزراعية،" دراسة تنسيق

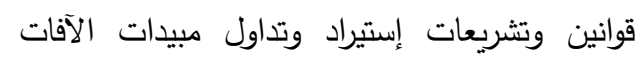
الزراعية فى الوطن العبى"، جامعة الدول العربية، .1996

7- المنظمة العربية للتتمية الزراعية،" الدورة التدريبية

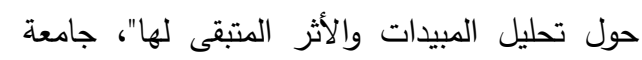

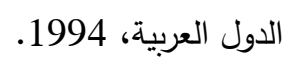

8- حبيش، محمد أحمد، أحمد محمد السيد، حمدى لإل

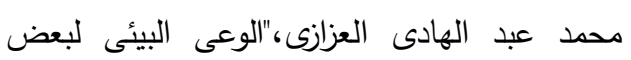

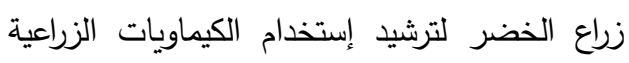
بمحافظة الشرقية"، المؤتمر الخامس، آفاق وتحديات

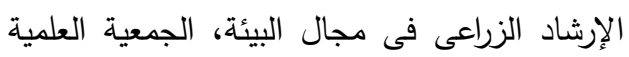

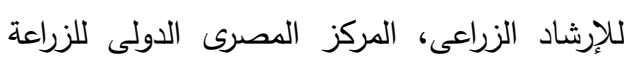

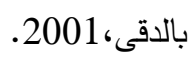

9- عبد الصدد، سالم عبد الحميد سالمه"تبنى مزارعى

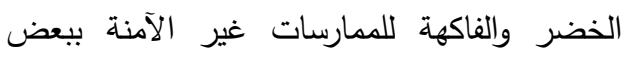

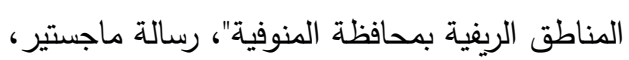
كلية الزراعة، جامعة المنوفية، 2013. 10- عبد العال، كريم سعد الدين محمد، "أثر السلوك الزعة

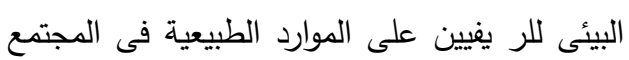

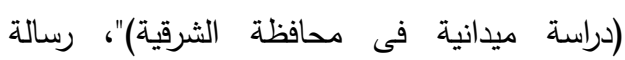
ماحستير، كلية الزراعة، جامعة الزقازيق، 2011 ـ

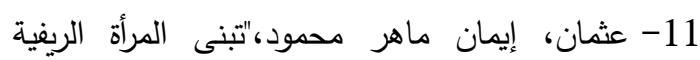

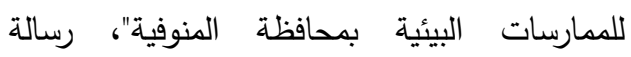
ماجستير ، كلية الزراعة، جامعة المنوفية، ,2009

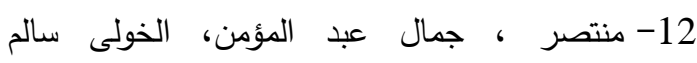
الخولى،"إدراك الزراع لأسس إستخدام المبيدات

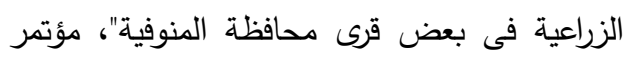

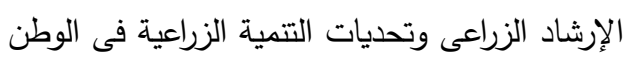

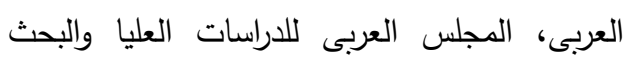

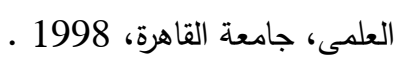

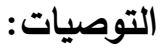

بناءاً على النتائج السابقة يمكن استخلاص التوصيات الآتية: - الاء 1-ضرورة إهتمام كل من وزارة الصحة وجهاز الإعلام بتقديم برامج توعية موجهة للمزارعين والمواطنين بخطورة التعامل مع المبيدات والأسمدة الكيماوية بشكل

$$
\text { خاطىء . خطورة التعاء }
$$

2- يجب على الجهاز الرقابى والتشريعى تغليظ القوانين

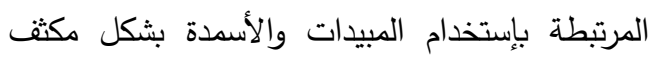

$$
\text { ومخالف لتوصيات وزارة الزراعة والبحث العلم. }
$$

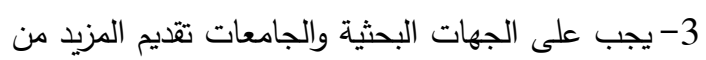

الدراسات والبحوث فى إمكانية الحد من استخدام

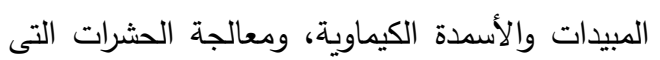
تصيب الأرض والنبات حيوياً "مكافحة متكاملة

$$
\text { 4- من الضرية". }
$$

\section{المراجع}

1- إبراهيم، عبدالله محمد، المبيدات سلاح ذو حدين، سلسلة العلوم والتكنولوجيا، مكتبة الأسرة، الكيئة المصرية العامة للكتاب ، 2009.

- - أرناؤوط، محمد السيد،"الإنسان وتلوث البيئة"، الهيئة العامة للكتاب، القاهرة، 1999. 3- الخولى، الخولى سالم إبراهيم،" التركيبة الإجتماعية

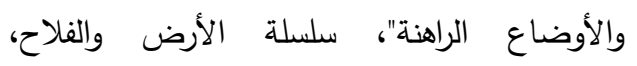
العدد(70)، 2013.

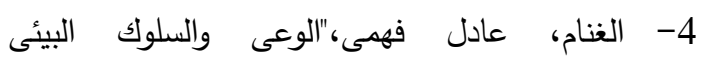

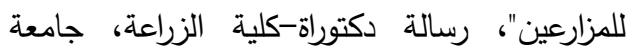
الأسكندرية، المزارعين، 2001.

5- الفصاص، وسام شحاته محمد السيد،" دراسة لبعض

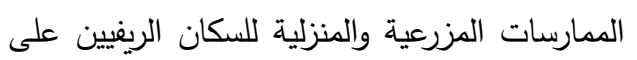

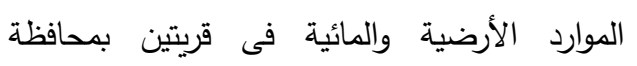




\title{
THE FARMERS KNOWING OF PRACTICES WHICH RELATED TO THE RATIONAL USAGE OF THE CHEMICAL PESTICIDES AND FERTILIZERS IN SOME VILLAGES IN ELSHARKIA GOVERNORATE
}

\author{
M. Hassan, Amina Sleem and Amany A. El Kholy \\ Agricultural Extension and Rural Development Research Institute
}

\begin{abstract}
The research aims at identifying the followings: the level of farmers knowing of practices which related to the rational usage of the chemical pesticides and fertilizers; the relationship between their knowing of practices and with some independent variables; and finally the lack reasons of their knowing.

This research was conducted in three villages in ElShakia governorate, the sample was selected randomly which reached 90 respondents, and used the questionnaire to collect the data by personal interview, this questionnaire was be pre-tested to insure its validity as a tool for collecting data, and data was presented and analyzed statistically by using frequencies; percentages; arithmetic mean; standard deviation; simple correlation coefficient of Pearson; analysis of variance; and Step Wise Multiple Regression Analysis.
\end{abstract}

The main findings were as the follows:

1- $64.4 \%$ and $83.3 \%$ of the respondents were had the middle level of knowing of practices which related to the rational usage of the chemical fertilizers and knowing of practices which related to the rational usage of the chemical pesticides respectively.

2- There was significant positive relationship between the farmers knowing degrees of practices which related to the rational usage of the chemical pesticides and fertilizers and with some independent variables that were: numbers of educational years; size of land holding; degree of formal social participation; multiple sources of information; degree of extension activities participation. There was significant negative relationship between the farmers knowing degrees of practices which related to the rational usage of the chemical pesticides and fertilizers and with the numbers of agricultural work experience.

3- The collective independent variables were interpreted $61.9 \%$ from total variance of farmers knowing of practices which related to the rational usage of the chemical pesticides; and were $62 \%$ farmers knowing of practices which related to the rational usage of the chemical fertilizers.

4- There were nine lack reasons of farmers knowing of practices which related to the rational usage of the chemical fertilizers and pesticides, and were ranked according to the reasons importance: there are fertilizers and pesticides unknown source and didn't covered with technical recommendations poster; there are invalid fertilizers for use in the markets; lack experience of extensioniests in the chemical fertilizers and pesticides field; rare progarmmes of awareness of the farmers o rational usage of the chemical fertilizers and pesticides; rare of the extension bulletins \& magazines which provide the correct information about the rational usage of the chemical fertilizers and pesticides.

So, the research recommended need attention from all governmental bodies which are health; control; media; and scientific research bodies and headed by extension organization and effective their roles; make extension \& applicable programmes that directed to rural people awareness with the danger wrong practices which related the rational usage of the chemical fertilizers and pesticides.

Key words: Practices - Rationalization - Chemical Fertilizers - Pest sides.

$$
\text { أسماء السادة المحكمين }
$$

